\title{
ОРГАНИЗАЦИЯ ПРЕСТУПНОГО СООБЩЕСТВА (ПРЕСТУПНОЙ ОРГАНИЗАЦИИ) ИЛИ УЧАСТИЕ В НЕМ (НЕЙ): ОТДЕЛЬНЫЕ ВОПРОСЫ КВАЛИФИКАЦИИ
}

\begin{abstract}
Аннотация: В статье рассматриваются некоторые вопросы квалификации действий организаторов и участников преступного сообщества (преступной организаџии), возникающие в процессе применения ст. 210 Уголовного кодекса Российской Федераџии. К их числу относятся 1) вопросы, связаннье с квалификацией по правилам реальной совокупности преступлений, 2) вопросы, связанные с наличием у членов преступной организации оружия, 3) вопросы, связанные с принуждением к участию в преступной организации. Объектом исследования выступают нормы уголовного закона и юридическая литература по данной тематике. Статья преимущественно построена на герменевтической методологии. Вместе с тем в качестве методологии также послужили положения теории уголовного права. Автором статьи формулируются соответствующчие правила квалификаџии по каждой из обозначенной выше ситуации, которые могут быть использованы в качестве определенной методологической базы в деятельности правоохранительных органов и суда и для дальнейших изысканий в науке уголовного права. Одновременно также даются рекомендации по изменению действующего уголовного законодательства Российской Федерации.
\end{abstract}

Ключевые слова: Преступное сообщество, преступная организация, вопросы квалификации, организованная группа, подстрекательство, объективное вменение, принуждение, вооруженность, квалифицирующий признак, уголовный закон.

Abstract: This article examines certain questions of qualification of the action of organizers and members of a criminal enterprise in the process of application of Article 210 of the Criminal Code of the Russian Federation. Such questions include: 1) questions pertaining to qualification by the rules of actual accumulation of crimes; 2) questions pertaining to possession of weapons by the members of the criminal enterprise; 3) questions that pertain to forceful participation in the criminal organization. The object of this research is the norms of criminal law and legal literature on this topic. The author formulates the corresponding rules of qualification for each of the aforementioned situations, which can be used as a certain methodological base in the work of the law enforcement agencies and courts, as well as for future research in the science of criminal law. The author also makes recommendations on possible changes to the current criminal legislation of the Russian Federation.

Keywords: Compulsion, objective imputation, incitement, organized crime, questions of qualification, criminal enterprise, criminal association, weapon possession, qualifying sign, criminal law.

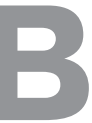

процессе применения ст. 210 Уголовного кодекса Российской Федерации [1] возникают определенные вопросы квалификации действий организаторов и участников преступной организации. Некоторые из них вызывают дискуссии в науке уголовного права, в рамках которых отдельные авторы вносят соответствующие предложения по изменению действующего уголовного законодательства. В первую очередь следует обратить внимание на п. 16 постановления Пленума Верховного суда РФ от 10 июня 2010 года № 12 «О судебной практике рассмотрения уголовных дел об организации преступного сообщества (преступной организации) или участии в нем (ней)» [2]. В соответствии с ним при совершении участником преступной организации преступления его действия подлежат квалификации по правилам реальной совокупности преступлений, при этом Пленум Верховного суда РФ указывает на необходимость вменения при квалификации при- знака «организованная группа», а если состав совершенного преступления не предусматривает названный квалифицирующий признак, то действия лица подлежат квалификации с учетом признака «группа лиц по предварительному сговору»; в случае отсутствия последнего вменяется признак «группа лиц». Поддерживают такую позицию высшего судебного органа, в части вменения признака «организованная группа», С.В. Петров [3, с. 100-101], Л.Д. Гаухман, С.В. Максимов [4, с. 21-22], Л.В. Глазкова [5, с. 111112], П. Агапов [6, с. 6].

На наш взгляд, такое правило квалификации, предложенное Пленумом Верховного суда РФ и поддерживаемое рядом ученых, не соответствует уголовному закону и допускает объективное вменение, то есть члены преступного сообщества несут ответственность за преступление, которое не совершали: вменяется преступление, совершенное в составе организованной группы (группы лиц по 
предварительному сговору, группы лиц), хотя де-юре и де-факто данные преступления совершались в составе преступного сообщества. А. Арутюнов верно замечает: «...суд должен будет в этом случае обосновать и наличие организованной группы, и наличие преступного сообщества. Однако оправданно полагать, что сделать это одновременно невозможно - либо организованная группа, либо сплоченная организованная группа. Если подсудимые являются членами организованной группы, то почему они же считаются участниками преступного сообщества (сплоченной организованной группы). Значит, квалифицировать их действия по ст. 210 УК РФ нельзя. Если же признавать их участниками преступного сообщества, то почему конкретное преступление ими совершено «всего лишь» в составе организованной группы. И опять квалификация их действий по совокупности будет вызывать недоумение» [7, с. 59].

Некоторые исследователи утверждают о необходимости квалификации действий участников преступной организации по совокупности ст. 210 и соответствующих статей Особенной части УК РФ без ссылки на признак «организованная группа», «группа лиц по предварительному сговору» или «группа лиц» [8, с. 104; 9, с. 166]. Вместе с тем, совершение преступления в составе преступной организации предлагается учитывать как обстоятельство, отягчающее наказание $[10$, с. 22,85$]$. Полагаем, что именно такая квалификация сегодня будет считаться основанной на уголовном законе, так как ни в одной статье УК РФ совершение преступления в составе преступного сообщества не предусмотрено в качестве квалифицирующего признака. Таким образом, действия участников преступной организации необходимо квалифицировать по ст. 210 и соответствующей статье Особенной части УК РФ без признака «группы», но учитывая при назначении наказания п. «в» ч. 1 ст. 63 УК РФ (совершение преступления в составе преступного сообщества).

Здесь интересно остановиться на следующем: в науке Д.В. Савельевым была высказана позиция, согласно которой в п. «в»ч. 1 ст. 63 УК РФ необходимо исключить совершение преступления в составе преступного сообщества как обстоятельство, отягчающее наказание. Аргументируется она тем, что «в случае совершения преступления преступной организацией ее участники несут ответственность по совокупности преступлений (ст. 210 УК РФ и соответствующая статья Особенной части Уголовного кодекса). Учитывая, что деяния участников группы уже квалифицированы по ст. 210 УК РФ, очевидно, что при назначении наказания за конкретное престу- пление нельзя рассматривать в качестве отягчающего обстоятельства выполнение его в составе преступного сообщества. Самостоятельно же, без применения ст. 210 УК РФ, совершение преступления в составе преступной организации не может учитываться как отягчающее обстоятельство» [11, с. 19]. К такому же выводу, используя такое же обоснование, приходит и С.В. Петров [3, с. 137-138].

На наш взгляд, с таким видением вопроса трудно согласиться. Утверждая, что квалификация по ст. 210 УК РФ исключает возможность применения п. «в» ч. 1 ст. 63 УК РФ, авторы изменяют природу этих норм. Дело в том, что наличие в уголовном законе ст. 210 и п. «в»ч. 1 ст. 63 обусловлено разными причинами. С одной стороны, повышенная общественная опасность самого факта создания преступной организации, руководства ей и участия в ней, с другой стороны, повышение степени общественной опасности конкретного преступления, совершаемого в составе преступной организации. В результате, с первой причиной связывается появление в уголовном законе ст. 210, со второй - появление п. «в» ч. 1 ст. 63. Таким образом, указанные выше доводы об исключении такого отягчающего обстоятельства как совершение преступления в составе преступной организации являются неубедительными.

Вместе с тем, в науке уголовного права многие исследователи обосновывают позицию о необходимости закрепления в статьях Особенной части УК РФ такого квалифицирующего признака как совершение преступления в составе преступного сообщества (преступной организации) [7, с. 59; 12, с. 76; 13, с. 13]. При этом некоторые из них одновременно предлагают исключить ст. 210 из уголовного закона [14, c. $350 ; 15$, с. 16$]$.

Мы полностью поддерживаем позицию о необходимости закрепления в Особенной части УК РФ такого квалифицирующего признака как совершение преступления в составе преступной организации. Такой квалифицирующий признак предусмотрен в уголовном законодательстве многих зарубежных стран (например, Испания, Мальта, Финляндия, Швейцария). Думается, необходимо воспринять такой опыт. Совершение преступления в составе преступной организации во много раз повышает степень его общественной опасности. Отсутствие данного признака в уголовном законе наряду с существованием такого как «совершение преступления группой лиц, группой лиц по предварительному сговору, организованной группой» безосновательно и, к тому же, ведет к нарушению принципа справедливости, закрепленного в ст. 6 УК РФ: так, например, убийство, совершенное 


\section{Право и политика $12(192) \cdot 2015$}

организованной группой, квалифицируется по ч. 2 ст. 105 и является основанием для назначения наказания вплоть до смертной казни, в то время как убийство в составе преступного сообщества, как было показано, должно подлежать уголовно-правовой оценке лишь по ч. 1 ст. 105 УК РФ. Введение квалифицирующего признака «совершение преступления в составе преступного сообщества (преступной организации)» существенно усилит борьбу с данной формой организованной преступности. Вместе с тем, подход, в котором параллельно речь идет об элиминировании ст. 210 из УК РФ, считаем малообоснованным. Аргументы сводятся, по существу, к тем же, которые упоминались выше применительно к п. «в» ч. 1 с. 63 УК РФ. Необходимо проводить четкое различие между криминализацией самого факта организации преступного сообщества или участия в нем и квалифицирующего признака, наличие которого во много раз повышает степень общественной опасности конкретного преступления. Такой подход никак не влечет нарушение принципа справедливости, установленного ст. 6 УК РФ.

Далее хочется остановиться на следующем. Если организатор, руководитель (лидер) или иной участник преступного сообщества незаконно владеет огнестрельным оружием, его действия в этой части надлежит квалифицировать по ст. 222 УК РФ, а также по соответствующей части ст. 210 УК РФ (п. 19 постановления Пленума Верховного суда РФ от 10 июня 2010 года № 12). В науке высказано мнение, что в ст. 210 УК РФ необходимо ввести квалифицирующий признак «вооруженность преступного сообщества», и установить повышенную ответственность за создание, руководство и участие в вооруженном преступном сообществе $[16 ; 13$, с. $13 ; 17$, с. 11$]$.

На наш взгляд, данный квалифицирующий признак будет излишним. Наличие оружия в преступной организации может иметь различные цели, причем как преступные, так и нет, например, оружие может использоваться лишь для самозащиты от конкурирующих преступных организаций или организованных групп. В отличие от банды, где целью ее существования всегда является нападение на граждан или организации, а наличие оружия явно облегчает достижение такой цели, в связи с чем вооруженность банды и признается конститутивным признаком состава, преступная организация не имеет такой определенной цели. Наличие у преступной организации, занимающейся, например, незаконным предпринимательством, оружия с неизбежностью влекло бы вменение признака вооруженности, хотя оружие могло применяться, а возможно такого случая и не наступило бы, лишь для защиты ее членов, что не свидетельствует о необходимости возложения более сурового наказания. По этим причинам, а так же в связи с тем, что всегда имеется возможность вменить ст. 222, 222.1 УК РФ, указанный признак думается нецелесообразно и нерезонно вводить в ст. 210 УК РФ.

Например, членам функционально обособленного структурного подразделения преступного сообщества - «группы безопасности», обеспеченного оружием, была отведена роль по обеспечению безопасности функционирования преступного сообщества и выполнению иных задач, направленных на обеспечение деятельности преступной организации, таких как: сопровождение сделок по сбыту наркотических средств, включающее в себя наблюдение, контрнаблюдение, в районе места их совершения; слежка, сбор информации о лицах, представляющих интерес для преступного сообщества; шантаж; защита участников преступной организации и их интересов, в случае возникновения конфликтов с представителями иных преступных группировок. Действия лиц, входящих в данное структурное подразделение, были, помимо прочего, квалифицированы по ст. 210 и ст. 222 УК РФ [18].

И, наконец, в науке уголовного права было высказано предложение о закреплении в уголовном законодательстве состава преступления, который бы предусматривал наступление уголовной ответственности за принуждение к участию в преступной организации [19, с. 10-11; 20, с. 16-17]. Думается, во включении подобного состава в текст уголовного закона нет необходимости. Такие действия должны быть квалифицированы как подстрекательство к участию в преступной организации, то есть по ч. 4 ст. 33 ч. 2 ст. 210 УК РФ, при условии, что потерпевший вошел в состав преступной организации. Если последнее исключается, то содеянное полностью охватывается ст. 210 УК РФ, а при наличии к тому оснований может повлечь и дополнительную квалификацию по иным статьям УК РФ (например, угроза убийством или причинением тяжкого вреда здоровью). Введение же подобного состава сделало бы бессмысленным существование общих норм, в частности норм о подстрекательстве, и, что более важно, привело бы к превращению уголовного закона в сборник частных случаев, казусов: принуждение к участию в банде, принуждение к участию в экстремистском сообществе, принуждение к участию в террористическом сообществе и т.д. Более того, действующий Уголовный кодекс РФ все же построен на акцессорной теории соучастия, при чем на такой ее разновидности как доктрина ограниченной акцессорности, в то время как принятие подобных норм явилось бы шагом к 
DOI: $10.7256 / 1811-9018.2015 .12 .17068$

При цитировании этой статьи сноска на doi обязательна

Закон и правопорядок

признанию теории самостоятельной ответственности соучастников.

В заключение важно отметить, что выше рассмотрены лишь некоторые вопросы квалификации, возникающие на практическом поле и обсуждаемые на страницах юридической литературы; однако уже они свидетельствует об отсутствии единой хорошо разработанной теории преступного сообщества (преступной организации) и необходимости дальнейшего исследования данной проблематики.

\section{Библиография:}

1. Уголовный кодекс Российской Федерации от 13 июня 1996 года № 63-Ф3 (ред. от 13.07.2015г.) // СПС КонсультантПлюс;

2. Постановление Пленума Верховного суда РФ от 10 июня 2010 года № 12 «О судебной практике рассмотрения уголовных дел об организации преступного сообщества (преступной организации) или участии в нем (ней)» // СПС КонсультантПлюс;

3. Петров С.В. Преступное сообщество как форма соучастия: проблемы теории и практики: моногр. / С.В. Петров. Н.Новгород: НИУ РАНХиГС, 2013;

4. Гаухман Л.Д., Максимов С.В. Уголовная ответственность за организацию преступного сообщества (преступной организации). Комментарий - М.: Учебно-консультационный центр «ЮрИнфоР», 1997;

5. Глазкова Л.В. Бандитизм и преступные сообщества: вопросы разграничения: монография. - М.: Юрлитинформ, 2013;

6. Агапов П. Организация преступного сообщества (преступной организации): некоторые проблемы юридической оценки // Уголовное право. 2006. № 2;

7. Арутюнов А. Организованные группы и преступные сообщества: вопросы квалификации // Законодательство и экономика. 2002. № 9 (221);

8. Даниленко Н.Н. Понятие и характеристика организованных преступных формирований // Закон. 2006. № 5;

9. Балеев С.А. Признаки организованной группы: проблемы доктринального и судебного толкования // Правовая политика и правовая жизнь. 2008. № 4;

10. Галиакбаров Р.Р. Борьба с групповыми преступлениями. Вопросы квалификации. Кубанский государственный аграрный университет, 2000;

11. Савельев Д.В. Преступная группа в сфере уголовной ответственности: Автореферат дисс. на соискание ученой степени канд. юрид. наук. Екатеринбург, 2000;

12. Виденькина Ж.В. К вопросу о совершенствовании законодательства об ответственности за организацию преступного сообщества или участие в нем // Закон и право. 2013. № 12;

13. Ермакова Т.Н. Банда и преступное сообщество (преступная организация) как формы соучастия: сравнительно-правовой анализ: Автореферат дисс. на соискание ученой степени канд. юрид. наук. М., 2009;

14. Козлов А.П. Соучастие: традиции и реальность. - СПб.: Издательство «Юридический центр Пресс», 2001;

15. Агапов П.В. Нужна ли в Уголовном кодексе РФ ответственность за создание организованной преступной группы? // Российская юстиция. 2006. № 3;

16. Глазкова Л. Совершение преступлений вооруженными участниками преступных сообществ (преступных организаций) // Законность. 2011. № 10;

17. Цветков Ю.А. Преступное сообщество (преступная организация): уголовно-правовой и криминологический анализ: Дисс. на соискание ученой степени канд. юрид. наук. М., 2004;

18. Приговор Оренбургского областного суда от 29 января 2013 года № 2-89/2012. [Электронный pecypc] http://www. sudrf.ru (дата обращения: 26.03.2015г.);

19. Черный А.В. Уголовная ответственность за организацию преступного сообщества (преступной организации) по законодательству России, Беларуси и Украины: сравнительный анализ: Автореферат дисс. на соискание ученой степени канд. юрид. наук. Рязань, 2005;

20. Скотинина В.Н. Компаративистское исследование состава организации преступного сообщества (преступной организации): внутригосударственный, международный и зарубежный аспекты: Автореферат дисс. на соискание ученой степени канд. юрид. наук. М., 2008.

\section{References (transliterated):}

1. Petrov S.V. Prestupnoe soobshchestvo kak forma souchastiya: problemy teorii i praktiki: monogr. / S.V. Petrov. - N.Novgorod: NIU RANKhiGS, 2013;

2. Gaukhman L.D., Maksimov S.V. Ugolovnaya otvetstvennost' za organizatsiyu prestupnogo soobshchestva (prestupnoi organizatsii). Kommentarii - M.: Uchebno-konsul’tatsionnyi tsentr «YurInfoR», 1997;

3. Glazkova L.V. Banditizm i prestupnye soobshchestva: voprosy razgranicheniya: monografiya. - M.: Yurlitinform, 2013;

4. Agapov P. Organizatsiya prestupnogo soobshchestva (prestupnoi organizatsii): nekotorye problemy yuridicheskoi otsenki // Ugolovnoe pravo. 2006. № 2;

5. Arutyunov A. Organizovannye gruppy i prestupnye soobshchestva: voprosy kvalifikatsii // Zakonodatel'stvo i ekonomika. 2002. № 9 (221);

6. Danilenko N.N. Ponyatie i kharakteristika organizovannykh prestupnykh formirovanii // Zakon. 2006. № 5; 
DOI: $10.7256 / 1811-9018.2015 .12 .17068$

При цитировании этой статьи сноска на doі обязательна

Право и политика $12(192) \cdot 2015$

7. Baleev S.A. Priznaki organizovannoi gruppy: problemy doktrinal'nogo i sudebnogo tolkovaniya // Pravovaya politika i pravovaya zhizn'. 2008. № 4;

8. Galiakbarov R.R. Bor'ba s gruppovymi prestupleniyami. Voprosy kvalifikatsii. Kubanskii gosudarstvennyi agrarnyi universitet, 2000;

9. Savel'ev D.V. Prestupnaya gruppa v sfere ugolovnoi otvetstvennosti: Avtoreferat diss. na soiskanie uchenoi stepeni kand. yurid. nauk. Ekaterinburg, 2000;

10. Viden'kina Zh.V. K voprosu o sovershenstvovanii zakonodatel'stva ob otvetstvennosti za organizatsiyu prestupnogo soobshchestva ili uchastie v nem // Zakon i pravo. 2013. № 12;

11. Ermakova T.N. Banda i prestupnoe soobshchestvo (prestupnaya organizatsiya) kak formy souchastiya: sravnitel'no-pravovoi analiz: Avtoreferat diss. na soiskanie uchenoi stepeni kand. yurid. nauk. M., 2009;

12. Kozlov A.P. Souchastie: traditsii i real'nost'. - SPb.: Izdatel'stvo «Yuridicheskii tsentr Press», 2001;

13. Agapov P.V. Nuzhna li v Ugolovnom kodekse RF otvetstvennost' za sozdanie organizovannoi prestupnoi gruppy? // Rossiiskaya yustitsiya. 2006. № 3;

14. Glazkova L. Sovershenie prestuplenii vooruzhennymi uchastnikami prestupnykh soobshchestv (prestupnykh organizatsii) // Zakonnost'. 2011. № 10;

15. Tsvetkov Yu.A. Prestupnoe soobshchestvo (prestupnaya organizatsiya): ugolovno-pravovoi i kriminologicheskii analiz: Diss. na soiskanie uchenoi stepeni kand. yurid. nauk. M., 2004;

16. Chernyi A.V. Ugolovnaya otvetstvennost' za organizatsiyu prestupnogo soobshchestva (prestupnoi organizatsii) po zakonodatel'stvu Rossii, Belarusi i Ukrainy: sravnitel'nyi analiz: Avtoreferat diss. na soiskanie uchenoi stepeni kand. yurid. nauk. Ryazan', 2005;

17. Skotinina V.N. Komparativistskoe issledovanie sostava organizatsii prestupnogo soobshchestva (prestupnoi organizatsii): vnutrigosudarstvennyi, mezhdunarodnyi i zarubezhnyi aspekty: Avtoreferat diss. na soiskanie uchenoi stepeni kand. yurid. nauk. M., 2008. 